\title{
The Mediating Role of Spirituality between Self-Value and Counselling Attitudes among Nigerian Students in Malaysian Universities
}

\author{
Idowu, G.T. ${ }^{1}{ }$, Hassan, S. A. ${ }^{2}$, Azimi, H. $^{3}$, Baba, M. ${ }^{4}$
}

\section{ABSTRACT}

This study examined the mediating role of spirituality between self-value and counselling attitudes towards seeking professional psychological help among Nigerian students in Malaysian universities. The sample consisted of 394 Nigerian students who are currently enrolled in 10 randomly selected universities across Malaysia. They completed self-report questionnaires administered one-on-one in each of the selected institutions. It was hypothesized that there is no mediating relationship between self-value and counselling attitudes through spirituality. Two levels of quantitative research are presented: descriptive and correlational. SPSS version 22 and SEM analyses (descriptive statistics/AMOS) gave a contrary result, therefore the null hypothesis was rejected and it was concluded that spirituality mediated the relationship between self-value and counselling attitudes. Limitations in the current study, such as sample size, and directions for future studies to address the limitations are discussed.

Keywords: Spirituality, Self-Value, Self-Worth, Self-Esteem, Counselling Attitudes, Nigerian Students.

\footnotetext{
${ }^{1}$ Faculty of Educational Studies, Department of Counsellor Education and Counselling Psychology, Universiti Putra Malaysia (UPM), Serdang, Selangor, Malaysia

${ }^{2}$ Faculty of Educational Studies, Department of Counsellor Education and Counselling Psychology, Universiti Putra Malaysia (UPM), Serdang, Selangor, Malaysia

${ }^{3}$ Faculty of Educational Studies, Department of Counsellor Education and Counselling Psychology, Universiti Putra Malaysia (UPM), Serdang, Selangor, Malaysia

${ }^{4}$ Faculty of Educational Studies, Department of Counsellor Education and Counselling Psychology, Universiti Putra Malaysia (UPM), Serdang, Selangor, Malaysia

*Responding Author

(C) 2016 I T Idowu, A Hassan, H Azimi, M Baba; licensee IJIP. This is an Open Access Research distributed under the terms of the Creative Commons Attribution License (http://creativecommons.org/licenses/by/2.0), which permits unrestricted use, distribution, and reproduction in any Medium, provided the original work is properly cited.
} 


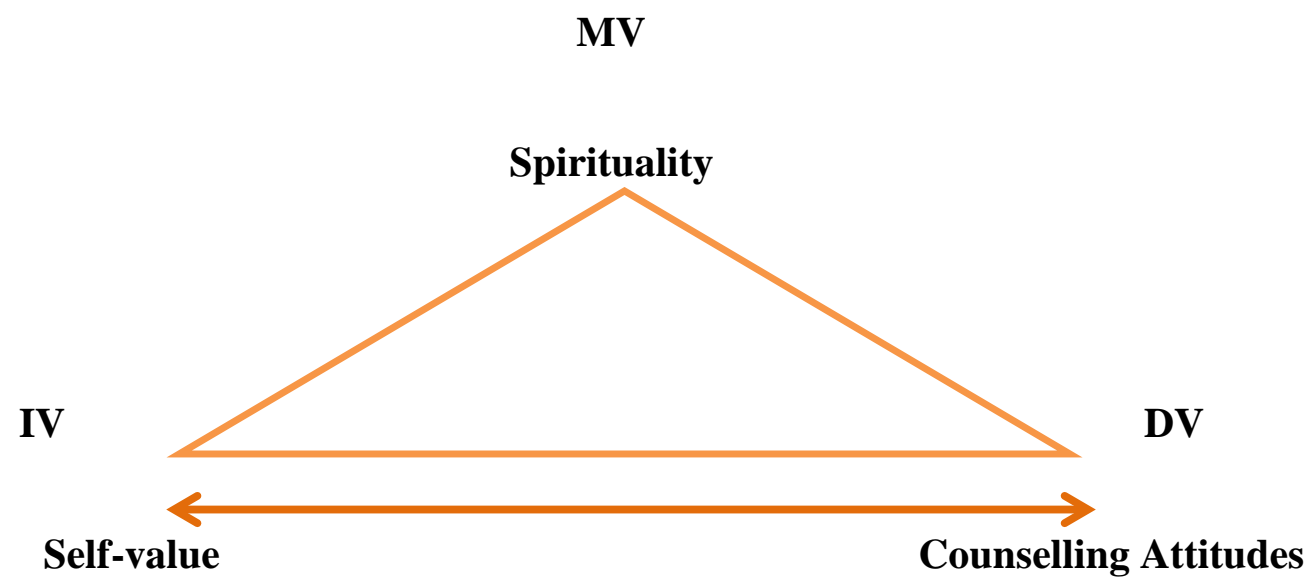

Figure i: The Conceptual framework

\section{BACKGROUND OF THE STUDY}

This present study has chosen to examine the counselling attitudes of Nigerian students in Malaysian universities because other research findings have confirmed that past experiences and individual's upbringing plays an important role in the formation of the person's attitudes (Nakamura and Csikszentmihalyi, 2014). Also, existing research findings in the domain of counselling psychology show that each of the two selected factors for examination in this study has a significant influence on counselling attitudes but as good as this may sound, only a relatively few studies focus on the Nigerian students in Malaysian universities; to examine how self-value, and spirituality as a mediator affect the counselling attitudes of these Nigerian students. Though few studies on help-seeking have included Nigerian students as participants (Aluede, 2008; Salami, 1998; Olutimehin, 1988; Laosebikan, 1980) but none has highlighted the counselling attitudes among Nigerian students in Malaysian universities, thereby creating the need for a study in which the findings will be entirely relevant to this population.

\section{Aims:}

The possible factor contributing to the counselling attitudes which is the focal point of this study is that many of the Nigerian students in Malaysian universities have found themselves being challenged by life outside Nigeria (Gebhard, 2012) because their perceptions and experiences of life abroad are totally contrary to their expectations, which are beyond reality (Eze, 2014). This affects these students psychologically and puts them in need of counselling.

The situational factor of the African culture and norms does not make the student in an unbearable situation overseas, to readily jump at the idea of returning home. This is because it is regarded as a thing of shame in the African culture, if you go abroad and return home emptyhanded; with no visible improvement in your financial status; it is like an unwritten 'taboo' (Carling and Carretero, 2008). 


\section{The Mediating Role of Spirituality between Self-Value and Counselling Attitudes among Nigerian Students in Malaysian Universities}

So with this conflict of values, returning home without achieving their aims of getting rich overseas is not usually considered an option by these students (Fioratta, 2015). In essence, the aspiration of some Nigerian students to make money abroad and the lack they met on getting to Malaysia, where there is a ban on employment for foreigners, is what is leading some of the students into risky behaviours earlier defined like drug-pushing, fraud (a.k.a.419), stealing, kidnapping and becoming a prostitute or gigolo, selling their body for money in a foreign land (Tive, 2006) because these students lack positive counselling attitudes. There is an urgent calling for counselling here in the sense that the feeling of disappointment eventually diminishes their self-value and worth for life; thereby leading some of them to acts of delinquencies (Soyinka, 1990). This disillusionment in turn affects their ability to have good and positive appraisal of themselves in order to make the right and acceptable decisions and put up good attitudes that can give Nigeria a good image in the world and promote peace in host nation Malaysia.

According to the Ministry of Higher Education Malaysia (MOHEM, 2012), Nigeria is rated among the top four countries that source international students into Malaysian universities. As one of the factors pointing at low self-esteem among the Nigerian students in Malaysia, in a report revealed by the MOHEM in 2010, out of over 5,217 cases of foreign students overstaying and immigration-related offences in Malaysia between 2010 and 2013, a total of 1,579 were Nigerians. "We have recorded 40 cases of violent crimes involving Nigerian students here, and 1,003 cases involved commercial crimes"... "We are concerned over the involvement of Nigerians in crime here in Malaysia” (Owoyemi, M. Y., Din, A. K. H., \& Sabri, A. Z. S. A., 2015). Statistics revealed that about 400 Nigerian students are now serving jail terms in Malaysian prisons for various offences (Owoyemi et al., 2015). This obviously calls for counselling.

Similarly, Christianity and Islam are the two religions mostly embraced in Nigeria on a 50:50 level (Olaniyan and Asuelime, 2014) hence an average Nigerian student in a Malaysian university is either a Christian or a Muslim, purportedly expected to be spiritually minded as a result of their proclaimed faith in these two religions (Haynes, 2014) yet some of them keep delving into various vices and put up attitudes that are unbecoming of a true Christian or a devout Muslim. Questions may then be raised that "Has their spirituality any mediating influence on the counselling attitudes they exhibit in host nation, Malaysia? Do their self-value affect the fight for survival in them to give themselves critical appraisal, guided by positive attitudes? When in need of counselling, what is their attitude towards seeking professional psychological help? These questions concerning the counselling attitudes of the sample population mainly accounts for the motivation behind the present study andthe research gaps it aims at bridging.

This problem deserves new research because there is a need to resolve the social problem of low self-value and negative counselling attitudes that is making some Nigerian students in Malaysian

(c) The International Journal of Indian Psychology, ISSN 2348-5396 (e)| ISSN: 2349-3429 (p) | 161 
The Mediating Role of Spirituality between Self-Value and Counselling Attitudes among Nigerian Students in Malaysian Universities

universities deviate from schooling into risky behaviours, in spite of their self-spirituality. Risky behaviour in this study is conceptualized asa lifestyle activity or a behavior that may result in a bad consequence for the Nigerian students and may prevent them from reaching their full capability and potential. The kind of behaviour which places one against one's self-value and sometimes against the norms of the society of abode.

\section{MAIN TEXT}

\section{Spirituality}

Recent researchers in the field of counselling psychology have identified the mediating role of spirituality in the relationships between constructs. Some came up with positive outcomes (Wang et al, 2008; Wallace \& Lahti, 2004), some indicated partial mediation (Reutter et al, 2014; Kelly et al, 2010; Utsey et al, 2007) while some reported negatively (Davis, 2005). Other studies also examined spirituality as a predictor (Steven et al, 2012; Salsman et al, 2005; Ironson et al, 2002). Nevertheless, it is theorized in this study that spiritual attachment helps develop individuals with good attitudes toward counselling.

Spirituality can be broadly defined as things that give sense to an individual's life (Bacik, 1996) within or without the context of religion. Therefore in this research, the term spirituality refers to the close relationship between the inner-soul of one's personality, beliefs and family practices surrounding it because spirituality represents a necessary essence of life that energizes both thought and actions of human beings (Taylor, 2007).

Spirituality can be experienced within or outside formal religious institutions. There are people who are not religious and have no belief in religion but they are spiritual (Fuller, 2011). For them, spirituality entails the search for an altered state of consciousness which enables them to be aware of cosmic realities that cannot be attained in normal states of consciousness. Many foreign students are deeply spiritual even though they do not take part in congregational life because they view their spirituality as a matter between the Creator and themselves. Selfspirituality resources might include practices of prayer, meditation or traditional faith-healing rituals. Spiritual nourishment is found in diverse ways even by individuals who ruminate themselves non-religious. This study however focuses on self-spirituality with religion.

Operationally in this study, Self-spirituality is defined as the spiritual inclination of the individual students that nurtures their sense of meaning and values personally or through parental guidance from the perspectives of both the Christian and Islamic religions: like caring for the needy, putting God first in every situation and so on. Self-spirituality results in a positive attitude which is emphasized by meditation. Spiritual people tend to analyze their inner-self, working towards ensuring that their actions are pure. When people are spiritual, they view themselves as 


\section{The Mediating Role of Spirituality between Self-Value and Counselling Attitudes among Nigerian Students in Malaysian Universities}

divine creations created in the image of God (Eck, 2014). This to them, implies that since they are created in God's image, they are perfect because God is perfect (Bible, 2011).

\section{Self-Value}

There is a mounting evidence that Self-value is one of the indispensable tools to succeed in life. It involves respecting others and feeling a sense of harmony and peace within oneself (Branden, 2011). Self-value is one of the important aspects affecting the qualities of human life in which lays the satisfaction of desire to be respected and loved ( $\mathrm{Li}, 2014)$. It also allows for a clearly defined connection to others in any part of the world. Every human being born with different physical and socioeconomic endowments like different talents, skills and family backgrounds has a certain amount of self-respect and everyone directly or indirectly longs for acceptance by others. Although some people like to value others above themselves, nevertheless, almost nobody believes that he or she is of no value.However, self-value diminishes through devaluing others. It is difficult to build oneself with a sense of self-resentment and resentment for others (Fisher and Exline, 2010). Devaluing oneself and others creates reciprocity and resistance with people living around (Mruk, 2013).

Operationally defined in this study, the combination of self-esteem and self-worth is what constitute self-value.

Past experiences have shown that self-esteem of an individual could either be high or low. If high, the individual acts effectively and decisively and he or she holds positive self-belief which makes him/her feel authentic and true to self. When it is low, it brings negative expectations which leads to high anxiety and low effort, which in turn leads to failure and self-blame. Similarly, past research indicates that overseas students often experience a low self-value because the environment they encounter is different from what they are accustomed to. The fact that they are away from their home, family and friends and they sometimes experience language barriers (Gonzalez, 2010), coupled with various challenges and psychological distresses they go through like culture shock (Pantelidou and Craig, 2006) leaves them demoralized with low selfvalue.

\section{Counselling Attitudes (towards seeking professional psychological help)}

Looking at counselling as a supportive relationship that helps a person to cope with certain areas of his or her life, counselling attitudes refer to the positive or negative evaluation that an individual has towards seeking counselling help, getting enlightenment and guidance, with an aim of bringing an understanding or awareness to a matter. For the purpose of this study, the counselling attitudes focus on the attitude of the Nigerian students in Malaysian universities in seeking professional psychological help and social support. 


\section{The Mediating Role of Spirituality between Self-Value and Counselling Attitudes among Nigerian Students in Malaysian Universities}

The current definition of Counselling put out by the British Association for Counselling and Psychotherapy (BACP, 2009) says that Counselling occurs when a Counsellor and a client meets in a confidential and discreet setting to both investigate a client's problem areas, which could be an unpleasant situation they may be passing through or lack of satisfaction with life, or even loss of a sense of direction and purpose.

Similarly, Bond (2015) defines counselling as a combinatorial process between a Counsellor who is trained and educated to give assistance to a client, who is vulnerable and needs the assistance of another person, in order to get his or her bearings well. The main purpose of the interaction between them is to enable the client to cope more effectively with him/herself and the reality of his situation (Cheong and Winikoff, 2005). Counselling is also a process where the client and Counsellor work together to come up with different ideas to handle various challenges of life.A good and supportive Counsellor is expected to give little or no direct advice, because the aim of the meeting is to help the individual to arrive at a solution through counselling; and for Counselling to be effective, it cannot be forcefully administered on an individual (Truax and Carkhuff, 2007); so it is mostly at the request of the client.

The attitude towards seeking professional counselling varies among different people, some are positive among students while with some others, the attitudes are usually negative (Vogel et al., 2005). Our attitude plays a crucial role in our personality. The attitude of the sample population affects their personality as they grow, travel to other countries, face challenges and take responsibilities. Attitudes generally affect all human activities and this made Winston Churchill to say that "Attitude is a little thing that makes a big difference" (Orr et al., 2008). There are different types of attitudes (Ajzen, 2005) like Social attitude, Individualistic attitudes, Theoretical attitudes, Traditional attitudes, Utilitarian attitudes, Aesthetic attitudes and so on. The focus of this study however, is the Counselling Attitudes of Nigerian students in Malaysian universities.

\section{Research Hypotheses}

$\mathbf{H o}_{1}$ : There are no significant mediating effects of spirituality existing between self-value and counselling attitudes among Nigerian students in Malaysian universities.

In summary, this research examines the role of self-spirituality as a mediator between self-value and counselling attitudes among Nigerian students in Malaysian universities through within the theoretical framework of the Person-Centered Counselling of Rogers (1951) which posited that every individual has a full capability for finding solutions to their own problems with the potential to fully understand them, without much intervention because they are capable of selfdirected growth.

(C) The International Journal of Indian Psychology, ISSN 2348-5396 (e)| ISSN: 2349-3429 (p) | 164 
MATERIALS AND METHOD

Measures

Self-Value

In this study, self-value was measured by the Self-Value Rating Scale (SVRS) which is a twodimensional instrument elaborated from a phenomenological conception of self-esteem and selfworth utilized in this study to collect quantitative information about the self-value of the selected sample as part of the research process.

SVRS consists of 10 items that capture the respondents' global perception of their own selfrespect and self-acceptance rated on a 5-point Likert-type scale, ranging from 5 (Always) to 1 (never). It was adapted by the researcher from the combination of 5 items from Self-esteem Rating Scale (SERS) of Nugent \& Thomas, (1993) and 5 items from the Self-Worth Quiz of Edith Cowan University in Australia (ECU, 2010), which measures self-esteem from a range area of self-evaluation including overall self-worth, social competence, problem-solving ability, intellectual ability, self-competence, and worth relative to other people. These two instruments are relevant scales of long standing reputation consisting of 40 items that provide a clinical measure on self-esteem (Nugent 2004) and 10 items that provide a psychometric measure on self-worth respectively. The items are summed to produce a total score ranging from -120 to +120. Positive scores mean more positive self-esteem and self-worth; on the other hand, negative scores indicate more negative self-esteem and self-worth.

\section{EFA for Self-Value}

To determine the factor structure among 10 items in a random sample of 200 excluded from main data set; Exploratory Factor Analysis (EFA) was applied . Various criteria for the factorability of a correlation were used. Firstly, the Kaiser-Meyer-Olkin (KMO) measure of sampling adequacy was 0.843, above the suggested value of .6, and Bartlett's test of sphericity was significant $\left(\chi^{2} 45=625.025, p<0.05\right)$. The diagonals of the anti-image correlation matrix were all over 0.5 , supporting the inclusion of each item in the factor analysis. Given these overall indicators, factor analysis was conducted with all 10 items related to Self-value items. The eigenvalues and total variance explained by the two components is presented in Table 1 . The results after Varimax rotation showed that the first factor explained $33.35 \%$ of the variance and the second factor $22.95 \%$ of the variance.

\section{Spirituality}

The Self-Spirituality Personality Inventory (SSPI) is a 5-item measure developed from the existing Universal Religious Personality Inventory (URPI) long form of 99 items developed by Azimi et al., (2012), which was considered too long for the practical purpose of capturing the only dimension of self-spirituality in this study. The five items selected from the URPI were 


\section{The Mediating Role of Spirituality between Self-Value and Counselling Attitudes among Nigerian Students in Malaysian Universities}

selected to represent the most salient proposed dimension of self-spirituality and are considered to be the most relevant ones out of the 99 items in the long form for this aspect.

The main purpose of developing the SSPI was to determine whether the measure would be significant based on self-spirituality alone and to provide items that are pertinent and relevant to both Christianity and Islam, the two religions under focus in this study. Also it provides an opportunity to get evidence of this scale's validity and reliability. Although the original scale was 99 items long and the measure itself is a religiosity scale; yet because spirituality and religiosity are interwoven and sometimes used interchangeably according to (Ironson et al., (2002); Woods, \& Ironson, (1999); Koenig et al,. 1997); therefore it made it possible for some items under religiosity to be relevant for use in spirituality issues and vice-versa as it were in this case. Craigie (1999) provided a rational for this interwoven nature of spirituality and religiosity when spirituality was defined as the inner dimension of all religious traditions that enhances an inter-religious view; hence these five selected items are relevant to self-spirituality because they directly measure the self-transcendence of the participants in this study.

For each item referring to their personal views or spiritual beliefs, respondents were asked to identify the practices that most accurately reflect their own by marking $(\checkmark)$ the appropriate box (from Always 5 to Never 1). The responses on the instrument were subjected to a principal components factor analysis with a varimax rotation. As it turned out, the five items fell under just one dimension of self-spirituality. The 5-items on the Self-Spirituality Personality Inventory (SSPI), together with the loadings (principal components with varimax rotation) on the factors to which each item pertains are presented in Table 1. An overall total was calculated (the sum of all the 5 items). It yielded an Alpha of 0.784 . This is quite high, agreed, although there are limitations to this instrument.

\section{Exploratory Factor Analysis (EFA) for Self-Spirituality}

Employing the Principal components analysis (PCA) and orthogonal method with varimax rotation, exploratory factor analysis (EFA) was also performed on the spirituality instrument (SSPI), using SPSS (version 22.0). This was applied to determine the factor structure among 5 items related to spirituality subscale in a random sample of 200 excluded from main data set. Several well-known criteria for the factorability of a correlation were used. Firstly, the KaiserMeyer-Olkin measure of sampling adequacy was 0.853 , above the suggested value of .6, and Bartlett's test of sphericity was significant $\left(\chi_{(10)}^{2}=571.93, \mathrm{p}<0.05\right)$. The diagonals of the antiimage correlation matrix were all over 0.5 , supporting the inclusion of each item in the factor analysis. Given these overall indicators, factor analysis was conducted with all 5 items related to spirituality items. One factor with eigenvalues greater than 1 was found with loading factors above 0.5. The eigenvalues and total variance explained by these components is presented in Table 2. The results showed that the only one factor explained $70.1 \%$ of the variance.

(C) The International Journal of Indian Psychology, ISSN 2348-5396 (e)| ISSN: 2349-3429 (p) | 166 
The Mediating Role of Spirituality between Self-Value and Counselling Attitudes among Nigerian Students in Malaysian Universities

\section{Counselling Attitudes}

Counselling Attitude was measured by the Attitudes toward Seeking Professional Psychological Help (ATSPPH-SF) Likert-type Scale of 5-1 of Always to Never respectively was adopted. It comprised of 10 items on counselling attitudes; based on four different dimensions namely: Recognition of Personal Need for Professional Help; Tolerance of Stigma Associated with Psychological Help; Interpersonal Openness; and Confidence in helpers. Scores are computed for each dimension. Positive attitudes toward seeking psychological help from professionals are represented by high scores on the ATSPPH. Four of the items are reverse scored, and higher overall scores are reflective of more favorable attitudes. Fischer and Farina (1995) reported psychometric properties of the shortened version including a correlation of .87 between scores from this instrument and the original form. The one-month test-retest reliability coefficient was .80 and the coefficient alpha was .84.

\section{Population of the Study}

The population is the totality of the elements under study, which in this research comprises of Nigerian students in Malaysian universities. The researcher's choice of using Nigerian students in Malaysian universities for this study predicated upon some cogent reasons, which are: The massive population of Nigerian citizens in Malaysia (approximately 10,000) in comparison with other nations of the world, as well as the ratio in comparison to the entire population of host nation, Malaysia (approximately 30 million in 2014). The population of this study includes the Nigerian students who are currently enrolled in any of the following Malaysian universities listed below in the location of the study

\section{Location of the Study}

Location of the study is West Malaysia. 10 universities were randomly selected from the number of universities in Malaysia. These are both private and public universities Universiti Malaya (UM), Universiti Putra Malaysia (UPM) and Universiti Teknologi Malaysia (UTM), Limkokwing University, Financial Technical and Management School (FTMS), UCSI University, INTI University, Linton University, Taylor’s University, and IUKL.

\section{Sample Size}

As at $1^{\text {st }}$ October, 2015, from the available records at the Nigerian High Commission, there are approximately 8,000 Nigerian students in Malaysian universities across the nation. A sampling size of 394 students was systematically drawn from the population of Nigerian students in ten different universities in Malaysia For a categorical data like this, a sample size of 367 is recommended by Kotrlik et al., (2001). 
The Mediating Role of Spirituality between Self-Value and Counselling Attitudes among Nigerian Students in Malaysian Universities

\section{Instrumentation}

Questionnaire was adopted as a research instrument in this study. The self-administered questionnaire was given to the respondent one-on-one. The respondents who participated in the research were given an ample time to respond to the items in the questionnaire to avoid inaccuracies and errors in their answers. The primary data were derived from the answers that the respondents gave in the self-administered questionnaire based on the Self-Value Rating Scale (SVRS), Self-Spirituality Personality Inventory (SSPI) and the Attitude Towards Seeking Professional Psychological Help (ATSPPH-SF) by Fischer and Farina (1995).

\section{Sampling Procedures}

The characteristics of the sample are expected to be the same with those of the population because it was selected with appropriate sampling technique. As such, a multistage cluster sampling technique was adopted. In the case of this study, cluster and random sampling was applied to get equal representations from the lists of students in the sampling frame obtained from the various schools selected as a complement to the list obtained from the Nigeria High Commission in Kuala Lumpur.

\section{Research Design}

This present study was conducted as a within-subject design, using a combination of descriptive quantitative and correlational research design in order to facilitate the discovery of measurable information and it also permits the inferences needed to examine the hypothesis and provide estimates in answer to the questions. The self-administered questionnaire was given to the respondent one-on-one. The respondents who participated in the research were given an ample time to respond to the items in the questionnaire to avoid inaccuracies and errors in their answers.

\section{RESULTS}

The mediation effect of Spirituality was assessed by using bootstrapping method for the path analysis. For the mediation result, if the direct score of the analysis is significant and the indirect with a mediator is also significant then the result is a partial mediation. If the direct score is significant but the indirect with a mediator is not significant, then the result is no mediation; but if the direct is not significant but the indirect with a mediator is significant, then the result is a full mediation. Both direct and indirect effects of self-value on counselling attitudes were significant which means that the effect of self-value on counselling attitudes was partially mediated by Spirituality. 
The Mediating Role of Spirituality between Self-Value and Counselling Attitudes among Nigerian Students in Malaysian Universities

Table i: Path Analysis result on the Hypothesis

\begin{tabular}{|l|l|l|l|l|}
\hline Alternative Hypothesis & Path & B & $\begin{array}{c}\text { P- } \\
\text { value }\end{array}$ & $\begin{array}{c}\text { Empirical } \\
\text { evidence }\end{array}$ \\
\hline $\begin{array}{l}\mathbf{H}_{\mathbf{1}} \text { : Self-spirituality mediated the } \\
\text { relationship between self-value } \\
\text { and counselling attitudes. }\end{array}$ & SV ------->SP---> CA & 0.057 & 0.022 & Supported \\
\hline
\end{tabular}

According to the results of path model after mediation self-value showed significant and positive effect on counselling attitudes after mediation $(\mathrm{B}=0.155, \mathrm{p}<0.001)$. The effect of self-spirituality on counselling attitudes was significant and positive $(\mathrm{B}=0.082, \mathrm{p}=0.002)$.

Table ii: Test of the total effects of Self-Value on Counselling Attitudes(with Mediator)

\begin{tabular}{|l|l|l|l|l|l|l|l|}
\hline \multicolumn{2}{|l}{ Path } & B & $\boldsymbol{\beta}$ & S.E. & C.R. & P \\
\hline SP & $<---$ & SV & 0.36 & 0.269 & 0.104 & 3.471 & $<0.001$ \\
\hline CA & $<---$ & SV & 0.155 & 0.298 & 0.047 & 3.332 & $<0.001$ \\
\hline CA & $<---$ & SP & 0.082 & 0.212 & 0.027 & 3.034 & 0.002 \\
\hline
\end{tabular}

SV: Self-value, SP: Self-Spirituality, PA: Parental Attachment, PEA: Peers Attachment, CA: Counselling Attitudes

\section{DISCUSSION}

Ho: $_{1}$ Self-spirituality does not mediate the relationships between self-value and counselling attitudes among Nigerian students in Malaysian universities.

The hypothesis stated that spirituality does not mediate the relationships between self-value and counselling attitudes. Using the bootstrapping method, the findings of this study showed a partial mediation because the direct and indirect effects are significant $(\boldsymbol{\beta}=0.057, p=0.022)$ as seen in table 4.14. The null hypothesis is therefore rejected hence the study concluded that indeed spirituality does mediate the relationships between self-value and counselling attitudes among Nigerian students in Malaysian universities. This result also uniformly aligns with existing literature. Frame, (2003) noted that one of the key fields of counselling is the field of addiction, which is often open to integration, spirituality and counselling.

This implication of the findings of this study on the Nigerian students in focus is that they could attain a high and positive self-value and have positive counselling attitudes if they are true to the religion they profess and pay good attention the their spiritual well-being. Spiritual beliefs and practices are salient in the conceptualization of well-being among Nigerian students in Malaysia. In connection with the sample population, the central importance of faith and spiritual practices e.g. prayer and spiritual counselling either through self - spirituality among Nigerian students may promote self-esteem, psychological well-being and positive counselling attitudes during

(c) The International Journal of Indian Psychology, ISSN 2348-5396 (e)| ISSN: 2349-3429 (p) | 169 
times of distress, grief and adversity. For instance, in studying south Asian immigrant families in coping responses after 9/11 terrorist attack, Cadge and Ecklund (2006) reported that spirituality was endorsed by the families as a cradle of strength and resilience for dealing with the loss of a loved one. Spirituality is generally viewed as a protective factor against suicide.

In relation to the instrument used to measure the self-concept, self-value is seen as relationship to other people as well as the self. It is one personal characteristic (a self-construct) that enable individuals to have a positive view of themselves in any situation they are (Mruk, 2013). In other words, a person with high self-value has a realistic view of himself and his worth which makes his or her comportment to be within the scope of societal norms (Mruk, 2013). While a person with low self-value behaves like he or she is worthless because that is the inner believe. It is this erroneous believe of inadequacy in oneself that makes an individual feel that other people would not like him or her. The feeling then makes the person to trust the competence of others more while having low opinion of himself; not realizing that nobody holds a good opinion of a man who holds a low opinion of himself (Trollope, 2015). This can also lead to nervous feelings when with strangers because the person believes that he or she might appear stupid to them.

A person with a high self-value holds the belief in the capacity to succeed at tasks thereby counting on him or herself to manage things well; while the person with low self-value behaves in ways others expected because of fear of being judged. This is contrary to Sheff (2015) who opined that as long as you look for someone else to validate who you are, by seeking their approval; you are setting yourself for disaster. Some individuals even find it difficult to accept who they are and always wish to be like other people; on this, Monroe (2015 remarked that it is a waste of the person you are created to be if you want to be someone else. It has also been argued by Vanzant (2015) that everything that happens to an individual is a reflection of what the person believes about himself. As explained earlier in the conceptual definition, self-value for the purpose of this study is being considered through two major sub-headings namely self-esteem and self-worth.

\section{CONCLUSION}

Several factors explored in this study through the self-administered questionnaire based on the three relevant instruments significantly predicted the mediating role of spirituality between selfvalue and counselling attitudes of the sample population. On the basis of the data gathered in relation to the statement of the problem and the objective, the most salient findings of this study is based on the data collected from 394 Nigerian students between the ages of 15 to 55 years, in ten Malaysian universities. SPSS and AMOS/SEM version 22 is used to analyze the entire data. Findings of the study based on the objectives, revealed that the null hypotheses tested, was rejected and it is concluded that there are significant mediating effects of spirituality existing between self-value and counselling attitudes among Nigerian students in Malaysian universities.

(c) The International Journal of Indian Psychology, ISSN 2348-5396 (e)| ISSN: 2349-3429 (p) | 170 


\section{The Mediating Role of Spirituality between Self-Value and Counselling Attitudes among Nigerian Students in Malaysian Universities}

This finding is consistent with majority of the investigations carried out earlier on the subject of self-value, spirituality and attitudes (Luquis et al., 2012; Berterö, 2002; Piedmont, 2001). For instance, Verplanken \& Holland (2002) in their research concluded that when values are cognitively activated and central to the self, they give meaning to, energize, and regulate valuecongruent behavior. The theoretical implication of this study is that spirituality has a significant mediating impact on the relationships between self-value and counselling as seen through the Structural Equation Modeling (SEM) analyses. This has contributed to existing understanding of the concept of self and the role of spirituality and its impact on counselling attitude in support of existing literature by Verplanken \& Holland (2002).

Ethical issues that arose while conducting the research came up in the area of the instruments. Two out of the three instruments combined to form the questionnaire used in this study were adapted from 2 major existing instruments. These are Self-Value Rating Scale (SVRS) adapted from Self-esteem rating scale (SERS) of Nugent (1993) and Self-Spirituality Personality Inventory (SSPI) adapted from Universal Religious Personality Inventory (URPI) of Azimi et al., (2012). According to Suskie (2010), a perfectly valid questionnaire must measure in such a way that allows an entirely accurate inferences to be drawn from it; making sure that each item is interpreted in the intended way; clear and easily understood with an intuitive relationship to the study's topic and objectives., and the intention behind each item is self-explanatorily clear to anyone knowledgeable about the topic. Reliability and validity are confirmed when the researcher takes precautionary steps like getting people with diverse backgrounds and viewpoints review the survey before administering it.

In order to establish the content validity, the selected items for the self-spirituality measure were sent to four content validity experts and two of the authors that developed the URPI (the mother instrument) for validation. There was a consensus from them all on the fact that the questions are representative of those that could be asked to evaluate self-spirituality of the sample population. A pilot study was also carried out in order to get feedback for refinement of the instrument. The concurrent validity was even tested by administering the instrument twice; though not on the same sample. The five items were subjected to a reliability analysis that yielded an alpha reliability coefficient of $0.853,0.863,0.863,0.767$, and 0.836 , respectively.

Similarly, in the on-going process of validating the newly adapted Self-Value Rating Scale (SVRS) for use, the researcher took certain precautionary steps in order to certify the face, content and construct validities by giving copies of the scale to four content validity experts in three different universities namely University Malaya, University of Ibadan, Nigeria and the head of department of Counsellor Education and Counselling Psychology, University Putra Malaysia; who studied them, and confirmed that they were good enough to measure what they intend to measure. Having read the items of the scales and confirmed that they actually measured

(c) The International Journal of Indian Psychology, ISSN 2348-5396 (e)| ISSN: 2349-3429 (p) | 171 
the variables of the study. A pilot study was also carried out to establish the content validity, test reliability and to explore the underlying dimensions of the SSPI. In this case, Cronbach's alpha is employed to assess the reliability index and it yielded .0820 for self-esteem and 0.855 for selfworth respectively. Accordingly, Principle Components Analysis is employed to explore the underlying dimensions of Self-Esteem and Self-Worth. SERS (the mother of SVRS) equally has an excellent reliability rating. Its internal consistency has an alpha of 0.97 and it is reported to be indicative of non-problematic attitudes (Fischer \& Corcoran, 2007b; Nugent, 2004). Details of the exploratory factor analysis (EFA) carried out for the two instruments are included in this article.

However, the limitations of the study are noteworthy. The very first and obvious limitation is the fact that a remarkably small number of only 5 items were selected to form the SSPI instrument out of the 99 items in the URPI as a result of practical considerations. It is remarkably possible that the gamut of the other dimensions of the complex concept of spirituality/religiosity have not been covered. Definitely, more dimensions are likely to be discovered if a large enough sample is obtained and the full 99 items are administered. Although sometimes the short form of an instrument does not reduce the dimensions and relevance of the measure as it was in the case of the Attitudes towards seeking professional psychological help instrument ATSPPH-SF by Fischer and Farina, (1995).

Secondly, the scope of the study focuses mainly on Nigerian students who are currently enrolled in any of the ten randomly selected universities for the study. Only ten out of the officially recognized seventy universities in Malaysia were involved due to logistics problems. However, the strength of the study lies in the fact that the results are very valid because the data was collected one-on-one. Secondly, it is the first of its kind on the counselling attitudes of Nigerian students in Malaysian universities. Further studies could be carried out on the sample population in other nations around the world, based on this foundation.

\section{Acknowledgement}

I hereby acknowledge that this work was graciously supported by the Geran Putra of Universiti Putra Malaysia, (UPM). Grant number = GP-IPS/2013/9399824

\section{REFERENCES}

Ajzen, I. (2005). Attitudes, personality, and behavior. McGraw-Hill Education (UK).

Aluede, O. (2008). A Roadmap to the Professionalization of Guidance and Counselling in Nigeria. Edo journal of counselling, 1(1), 1-15.

Azimi, H., Krauss, S.E., Sidek, M.N., Turiman, S., Rumaya, J., Jamiah, M... (2007). Muslim religiosity and personality assessment: Prototype for nation building. Serdang: Instittut Pengajian Sains Social.

Bacik, J. J. (1996). Spirituality in transition: Rowman \& Littlefield. Maryland, USA.

(C) The International Journal of Indian Psychology, ISSN 2348-5396 (e)| ISSN: 2349-3429 (p) | 172 


\section{The Mediating Role of Spirituality between Self-Value and Counselling Attitudes among Nigerian Students in Malaysian Universities}

BACP (2009). Reach and connect. BACP definition of counselling. (British Association of Counselling \& Psychotherapy). Retrieved from http://reachandconnect.com/content/view/32/25/

Berterö, C. M. (2002).Affected self-respect and self-value: the impact of breast cancer treatment on self-esteem and QoL. Psycho-Oncology, 11(4), 356-364.

Bible, C. E. (2011). The Holy Bible.Cambridge University Press.

Bond, T. (2015). Standards and ethics for counselling in action. Sage.

Branden, N. (2011). Honoring the self: The psychology of on fidence and respect. Bantam.

Cadge, W., \& Ecklund, E. H. (2006). Religious service attendance among immigrants evidence from the new immigrant survey-pilot. American Behavioral Scientist, $\quad 49(11), 1574-1595$.

Carling, J., \& Carretero, M. H. (2008, September).Kamikaze migrants? Understanding and tackling high-risk migration from Africa. In conference Narratives of Migration Management and Cooperation with Countries of Origin and Transit (pp. 18-19).

Cheong, C., \& Winikoff, M. (2005). Hermes: Designing goal-oriented agent interactions. In Agent-Oriented Software Engineering VI (pp. 16-27).Springer Berlin Heidelberg.

Craigie, F., \& Hobbs, R. (1999).Spiritual perspectives and practices of family physicians with an expressed interest in spirituality.Family medicine-kansas city-, 31, 578-585.

Cronbach, L. J. (1951). Coefficient alpha and the internal structure of tests. psychometrika, 16(3), 297-334.

Davis, B. (2005). Mediators of the relationship between hope and well-being in older adults. Clinical Nursing Research, 14(3), 253-272.

Eck, D. L. (2014). Encountering God: A spiritual journey from Bozeman to Banaras. Beacon Press.

ECU, (2010). Edith Cowan university self-worth quiz. Retrieved from http://www .altcleadership.ecu.edu.au/wp-content/uploads/2010/12/Activity-2.0-Selfworth-quiz.pdf

Eze, E. O. (2014). Exploring international students experiences of studying in UK universities: a narrative inquiry of Nigerian students (Doctoral dissertation, Anglia Ruskin University).

Fioratta, S. (2015). Beyond remittance: Evading uselessness and seeking personhood in Fouta Djallon, Guinea. American Ethnologist, 42(2), 295-308.

Fischer, J., \& Corcoran, K. (2007). Measures for clinical practice: A source book. Volume 1: Couples, families, and children. New York, NY: Oxford University Press.

Fischer, E. H., \& Farina, A. (1995). Attitudes toward seeking professional psychological help: shortened form and considerations for research. Journal of College Student Development, 36(4), 368-373

Fischer, E. H., \& Turner, J. I. (1970). Orientations to seeking professional help: development and research utility of an attitude scale. Journal of consulting and clinical psychology, 35(1), 79

Fisher, M. L., \& Exline, J. J. (2010).Moving toward self-forgiveness: Removing barriers related to shame, guilt, and regret. Social and Personality Psychology Compass, 4(8), 548-558

Frame, M.W. (2003).Integrating religion and spirituality into counselling: A comprehensive approach. Pacific Grove, CA: Thomson/Brooks-Cole.

Fuller, S. (2011). Humanity 2.0: What it means to be human past, present and future. Palgrave Macmillan Ltd.

Gebhard, J. G. (2012). International students' adjustment problems and behaviors. Journal of International Students 2012 Vol 2 Issue 2, 158. 


\section{The Mediating Role of Spirituality between Self-Value and Counselling Attitudes among Nigerian Students in Malaysian Universities}

González, C. R., Mesanza, R. B., \& Mariel, P. (2011).The determinants of international student mobility flows: an empirical study on the Erasmus programme. Higher Education, 62(4), 413-430.

Hale , M. (2015) Quote by Mandy Hale. Retrieved at http://www.goodreads.Com /quotes/861919-you-will-never-gain-anyone-s-approval-by-begging-for-it.

Haynes, J. (2014). Religion in global politics. Routledge.

Ironson, G., Solomon, G. F., Balbin, E. G., O’Cleirigh, C., George, A., Kumar, M., \&Woods, T. E. (2002). The Ironson-Woods Spirituality/Religiousness Index is associated with long survival, health behaviors, less distress, and low cortisol in people with HIV/AIDS. Annals of Behavioral Medicine, 24(1), 34-48.

Kelly, J. F., Stout, R. L., Magill, M., Tonigan, J. S., \& Pagano, M. E. (2011). Spirituality in recovery: A lagged mediational analysis of Alcoholics Anonymous’ principal theoretical mechanism of behavior change. Alcoholism: Clinical and Experimental Research, 35(3), 454-463.

Koenig, H., ParkersonJr, G. R., \& Meador, K. G. (1997).Religion index for psychiatric research.

Kotrlik, J. W. K., \& Higgins, C. C. H. (2001). Organizational research: Determining appropriate sample size in survey research appropriate sample size in survey research. Information technology, learning, and performance journal, vol.19(1), 43.

Laosebikan, S. (1980). On the resistance of Principals and teachers to the introduction of guidance and counselling services in secondary schools in Oyo State. The Counsellor 3, 57-64.

Li, D. (2014). Types of value.In value theory (pp. 67-97).Springer Berlin Heidelberg.

Lincoln (2015).Meetville. Abraham Lincoln quotes and sayings. Retrieved from https://meetville.com/quotes/author/abraham-lincoln/page1

Luquis, R. R., Brelsford, G. M., \& Rojas-Guyler, L. (2012).Religiosity, spirituality, sexual attitudes, and sexual behaviors among college students. Journal of religion and health, 51(3), 601-614.

MoHEM, (2012).Ministry of Higher Education, Malaysia. Retrieved from https://en.wikipedia.org/wiki/Ministry_of_Higher_Education_Malaysia.(Accessed, August, 2015)

Monroe, M. (2015).Goodreads. Marilyn Monroe > quotes. Retrieved from http://www.goodreads.com/author/quotes/82952.Marilyn_Monroe?page=2 Mruk, 2013)

Mruk, C. J. (2013). Self-esteem and positive psychology: Research, theory, and practice. Springer Publishing Company.

Myer (2008).Quotes on Attitudes. Retrieved at http://www.quotehd.com/quotes/paul-myerquote-attitudes-are-nothing-more-than-habits-of-thoughts-and-habits

Nakamura, J., \& Csikszentmihalyi, M. (2014). The concept of flow. In Flow and the Foundations of Positive Psychology (pp. 239-263). Springer Netherlands.

Nugent, W. R. (2004). A validity study of two forms of the Self-Esteem Rating Scale. Research on Social Work Practice, 14(4), 287-294.

Nugent, W. R., \& Thomas, J. W. (1993).Validation of a clinical measure of self-esteem. Research on Social Work Practice, 3(2), 191-207.

Olaniyan, A., \& Asuelime, L. (2014).Boko haram insurgency and the widening of cleavages in Nigeria. African Security, 7(2), 91-109.

Olutimehin, J.T.B. (1988). Analysis of undergraduates use of the College Counselling Centre. Nigerian Journal of Counselling and Development, 2, (I), 69 14. 


\section{The Mediating Role of Spirituality between Self-Value and Counselling Attitudes among Nigerian Students in Malaysian Universities}

Orr, J. W., Naumann, W. R., \& Escobar, P. (2008). "Attitude is a little thing that makes a big difference” Winston Churchill. Gynecologic oncology, 109(1), 147-151.

Oskamp, S., \& Schultz, P. W. (2005). Attitudes and opinions. Psychology Press.

Owoyemi, M. Y., Din, A. K. H., \& Sabri, A. Z. S. A. (2015). The diaspora Nigerians' image problem of drug and fraud: A case study of the Malaysian-Indonesian experience through newspaper reports. Journal of Social Sciences, 11(2), 55.

Pantelidou, S., \& Craig, T. K. (2006).Culture shock and social support. Social psychiatry and psychiatric epidemiology, 41(10), 777-781.

Piedmont, R. L. (2001). Spiritual transcendence and the scientific study of spirituality. Journal of rehabilitation, 67(1), 4.

Reutter, K. K., \&Bigatti, S. M. (2014). Religiosity and spirituality as resiliency resources: moderation, mediation, or moderated mediation?.Journal for the scientific study of religion, 53(1), 56-72.

Rogers, C. R. (1951). Client-centered therapy: Its current practice, implications and theory (p. 491). Boston: Houghton Mifflin.

Salami, S. O. (1998).Attitudes towards counselling among rural college students in Nigeria. Ife PsychologiA: An International Journal, 6(2), 116-31

Salsman, J. M., Brown, T. L., Brechting, E. H., \& Carlson, C. R. (2005). The link between religion and spirituality and psychological adjustment: The mediating role of optimism and social support. Personality and social psychology bulletin, 31(4), 522-535.

See, C. M., \& Ng, K. M. (2010). Counseling in Malaysia: History, current status, and future trends. Journal of Counseling \& Development, 88(1), 18-22.

Sheff, N. (2015). Goodreads.Nic Sheff $>$ Quotes. Retrieved from http://www.goodreads.com/author/quotes/353227.Nic_Sheff

Soyinka, W. (1990).Twice bitten: The fate of Africa's culture producers. Publications of the Modern Language Association of America, 110-120.

Stevens-Long, J., Schapiro, S. A., \& McClintock, C. (2012). Passionate scholars: Transformative learning in doctoral education. Adult Education Quarterly, 62(2), 180-198.

Suskie, L. (2010). Assessing student learning: A common sense guide. John Wiley \& Sons.

Taylor, R. J., Chatters, L. M., \& Jackson, J. S. (2007). Religious and spiritual involvement among older African Americans, Caribbean blacks, and non-Hispanic whites: Findings from the national survey of American life. The Journals of Gerontology Series B: Psychological Sciences and Social Sciences, 62(4), 238-250.

Tive, C. (2006). 419 scam: Exploits of the Nigerian con man. iUniverse.

Tracy, B. (2015). Meetville. Brian Tracy quotes and sayings. Retrieved from https://meetville.com/quotes/author/brian-tracy/page1

Trollope, A. (2015). Meetville. Anthony Trollope quotes and sayings. Retrieved from https://meetville.com/quotes/author/anthony-trollope/page1

Truax, C. B., \& Carkhuff, R. (2007). Toward effective counseling and psychotherapy: Training and practice. Transaction Publishers.

Utsey, S. O., Bolden, M. A., Williams, O., Lee, A., Lanier, Y., \& Newsome, C. (2007). Spiritual well-being as a mediator of the relation between culture-specific coping and quality of life in a community sample of African Americans. Journal of Cross-Cultural Psychology, 38(2), 123-136.

Vanzant, I. (2015) Goodreads. Iyanla Vanzant > quotes. Retrieved from

(c) The International Journal of Indian Psychology, ISSN 2348-5396 (e)| ISSN: 2349-3429 (p) | 175 
The Mediating Role of Spirituality between Self-Value and Counselling Attitudes among Nigerian Students in Malaysian Universities

http://www.goodreads.com/author/quotes/15508.Iyanla_Vanzant

Verplanken, B., \& Holland, R. W. (2002). Motivated decision making: effects of activation and self-centrality of values on choices and behavior. Journal of personality and social psychology, 82(3), 434.

Victor, C. J. (2014). Statistics show that Nigerians are problematic Africans in Malaysia. The ant daily. Retrieved from http://www.theantdaily.Com/Article.aspx?ArticleId=6807

Vogel, D. L., Wester, S. R., Wei, M., \& Boysen, G. A. (2005).The Role of Outcome Expectations and Attitudes on Decisions to Seek Professional Help. Journal of Counseling Psychology, 52(4), 459.

Wallace, K., \& Lahti, E. (2004, October).Spirituality as a mediator of the relation between perceived stress and life satisfaction. In Gerontologist (Vol. 44, pp. 567-567).1275 k street nw suite 350, Washington, dc 20005-4006 USA: Gerontological society amer.

Wang, C. W., Chan, C. L. W., Ng, S. M., \&Ho, A. H. Y. (2008). The impact of spirituality on health-related quality of life among Chinese older adults with vision impairment. Aging and Mental Health, 12(2), 267-275.

Woods, T. E., \& Ironson, G. H. (1999).Religion and Spirituality in the Face of Illness How Cancer, Cardiac, and HIV Patients Describe their Spirituality/Religiosity. Journal of Health Psychology, 4(3), 393-412.

How to cite this article: T Idowu, A Hassan, H Azimi, M Baba (2016), The Mediating Role of Spirituality between Self-Value and Counselling Attitudes among Nigerian Students in Malaysian Universities, International Journal of Indian Psychology, Volume 3, Issue 4, No. 57, ISSN 2348-5396 (e), ISSN: 2349-3429 (p), DIP: 18.01.037/20160304, ISBN: 978-1-365-239939

(c) The International Journal of Indian Psychology, ISSN 2348-5396 (e)| ISSN: 2349-3429 (p) | 176 